\title{
An Investigation of the Relationship Between Corporation Social Responsibility and Senior Managers Influence \& Poverty Experience
}

\author{
Qiang Zhang ${ }^{1, ~ *}$, Bo Wang ${ }^{2,3}$, ChengZhong Liao ${ }^{4}$ \\ ${ }^{1}$ School of Economics and Management, Southwest University of Science and Technology, Mianyang, P. R. China \\ ${ }^{2}$ School of Civil Engineering and Architecture, Southwest University of Science and Technology, Mianyang, P. R. China \\ ${ }^{3}$ School of Economics and Management, Southwest Jiaotong University, Chengdu, P. R. China \\ ${ }^{4}$ School of Marxism, Southwest University of Science and Technology, Mianyang, P. R. China
}

Email address:

393831787@qq.com (Qiang Zhang),boy5240@163.com (Bo Wang)

${ }^{*}$ Corresponding author

\section{To cite this article:}

Qiang Zhang, Bo Wang, ChengZhong Liao. An Investigation of the Relationship Between Corporation Social Responsibility and Senior Managers Influence \& Poverty Experience. Journal of Finance and Accounting. Vol. 8, No. 1, 2020, pp. 1-8. doi: 10.11648/j.jfa.20200801.11

Received: November 21, 2019; Accepted: January 3, 2020; Published: January 4, 2020

\begin{abstract}
The high-level echelon theory states that business executives are not"fully rational people"with economic assumptions in actual work. The management decision-making process of business executives is often affected by cognitive abilities, values and moral emotion. Taking the A-share listed companies in China from 2012 to 2015 as the research object, this paper analyzes the impact of the interaction between senior managers' influence and their poverty experience on the corporate social responsibility. This study indicates that the senior managers' poverty experience enhances the sense of corporate social responsibility. When the sub-index of senior managers' influence and poverty experience are tested by analysis of regression, it is found that compared with the poverty environment of managers' early experience, their three-year difficult period experience and special poverty experience have played a more significant role in strengthening the positive correlation between the senior managers' influence and the corporate social responsibility. This investigation is helpful and beneficial for further studies on the "altruism" factors of corporate social responsibility and it could enrich the theoretical system of corporate social responsibility.
\end{abstract}

Keywords: Senior Managers’ Influence, Poverty Experience, Interaction Effect, Corporate Social Responsibility

\section{Introduction}

With regard to the relationship between senior managers' influence and poverty experience on corporate social responsibility, Geert Hofstede, a famous psychologist in the Netherlands, holds the opinion that the power distance determines power (rights) desire [1]. The farther away individuals are from their rights, the stronger their demands and desires are. For managers who lived in poverty in the early years, the stronger the desire of rights (such as future achievements, getting respect from others, etc.) is, the stronger the will to change their fate will be; the greater the power is, the more obvious the tendency towards collectivism and social services will be. Senior managers with poverty experience trend to hold a stronger sense of social responsibility, once they become the leader of enterprise and own significant rights. "Mencius", a famous Confucian book in China, in the chapter of "under the notice," it mentions that "whenever heaven invests a person with great responsibilities, it first exercises his mind with suffering, and his muscles and bones with toil. It exposes his body to hunger, and subjects him to extreme poverty. In this way his patience and endurance are developed and his weakness is overcome. "Zhang Zai, a famous thinker and educator in the Northern Song Dynasty, once said in "Ximing" that "Poverty and sorrow, where accomplishments are from." The early experience of suffering difficult can hone one's will of striving for strength. In order to success, one must undergo the ordeal of hardship." Therefore, for senior managers, the early experience can temper their willpower as well as perseverance. Furthermore, in that way can the experience provide the soil for their later growth, the 
improvements of their influence and the ideology of serving the society.

In the existing research, Hambrick and Mason pointed out in the senior echelon theory that senior managers are not "completely rational" assumed by economics in practice. The management and decision-making process of senior managers are often affected by cognitive ability, values and moral emotion. The higher the influence of senior managers is, the greater the impact of personal experience on the management and decision-making process will be. With regard to the impact of senior managers' professional experience of social responsibility, Benmelech and Frydman (2015) believe among the influence of age, working background and experience of education, the poverty experience of managers has a more profound impact on the formation of corporate social responsibility [2]. The more managers suffered from the poverty experience, the stronger the effect will be. In the relevant researches of Chinese scholars, Joe (2009) state that the promotion of senior managers' personal influence on corporate social responsibility decision-making will also be affected by other factors [3]. Slater (2009) believe that poverty experience as an intermediate variable can strengthen managers' social responsibility strategy and performance, when studying the relationship between poverty experience and charitable donation [4].

Based on the above points of view and analysis, this paper takes the sample of A-share listed companies in China from 2012 to 2015 as the research objects, and from the perspective of the interaction between senior managers' influence and early poverty experience, this paper analyzes the impact of their interaction on the performance of corporate social responsibility, in order to draw new research conclusions. This paper have some contributions, there are few relevant literature about the impact of managers' early poverty experience and later influence on the performance of corporate social responsibility. This paper will empirically test the impact of interaction between senior managers' influence and poverty experience on corporate social responsibility performance, and analyzes if there is a strengthening effect of poverty experience towards the interaction between senior managers' influence and corporate social responsibility performance. Different poverty experience dimensions have different poverty intensity or degrees. Compared with the poverty environment experience of senior managers in their early years, the three-year hard period experience and the special poverty experience have greater effects. Therefore, whether there are differences among different degrees of poverty which have an impact on the corporate social responsibility when interacting with senior managers' influence, is also a key issue to be further resolved through empirical evidence in this section; This paper will further confirm the importance of promoting corporate social responsibility performance of managers. This may help the theoretical and practical researchers to further grasp the "altruism" factors affecting the fulfillment of corporate social responsibility.

\section{Theoretical Analysis and Research Hypothesis}

The influence of the peak period of senior managers' career and the early experience of poverty are at two different stages of senior managers (Figure 1). Regarding the mechanism of the interaction between the two factors on corporate social responsibility, some scholars have studied and believe that the senior managers who experienced poverty in the early period, which have had a profound impact on childhood psychology, would be subtly influenced in terms of their formation of their early values. Kuhnen C, Niessen (2009) studying the impact of poverty on individual career planning, found that individuals who experienced poverty tend to be more likely to put themselves in others' shoes during their careers, and more likely to be in the same wavelength with people who suffered from the same experience [5]. With the domination of resources and ability of making decisions, these individuals will try their best to express our feelings of concern and support. Thus, when individuals with poverty experience become senior managers, as they have their own profound understanding of poverty in their mind, they are more likely to be considerate of others' feelings, and place themselves in others' position. When social responsibility calls, these senior managers are more likely to get touched, they will actively fulfill their responsibility to express their humanistic care.

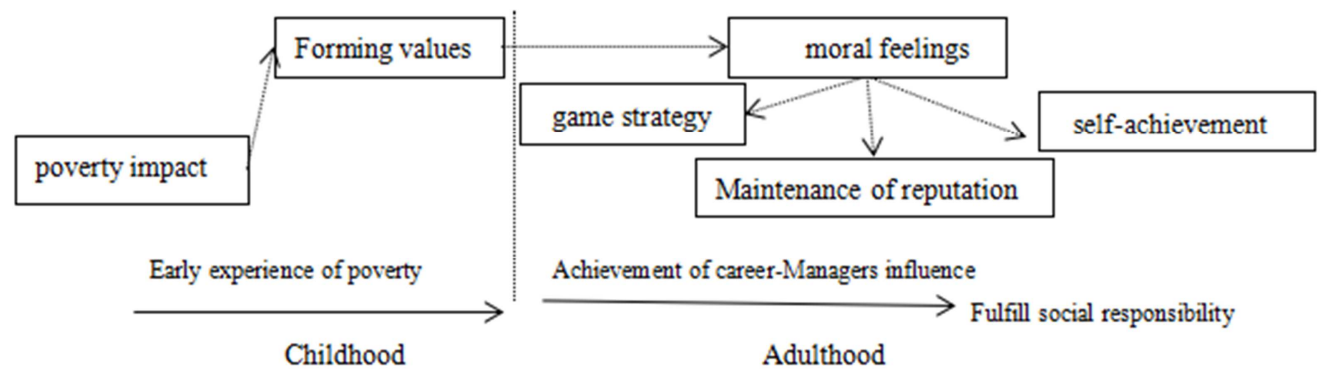

Figure 1. Pathways in which managers influence and poverty experiences affect corporate social responsibility.

With regard to the interaction between senior managers' influence and poverty experience in influencing corporate social responsibility performance, this paper argues that poverty experience is an early life experience that affects senior managers' personality psychology and compassion formation, and its influence on the correlation of senior 
managers and corporate social responsibility may be positive. The reasons are as follow. On the one hand, from the perspective of managers' reputation, the greater the influence of managers is, the more managers with poverty experience will cherish the hard-won external trust and prestige, and are the more willing to maintain and strengthen through active fulfillment of social responsibilities [6]. On the other hand, according to Hofstede's value theory and high-level echelon theory analysis, the greater the influence of senior managers is, the greater the society's expectations of senior managers and the more social responsibility needs to be faced by the companies will be. Senior managers with poverty experience are more likely to put themselves in the shoes of others, and their inner moral feelings are more likely to be touched [7]. The poverty experience of senior managers will shift the motivation of fulfilling social responsibility from the economic motivation or rule arrangement to the moral and emotional cognition of the senior managers. Based on these, this paper proposes hypothesis 1: Senior managers' influence and poverty experience have complementary relationships in affecting corporate social responsibility performance.

This paper measures the poverty experience of senior managers in the three dimensions, including poverty environment experience, three-year hard period experience and special poverty experience. Due to the different degrees of the poor environment, three-year hard period and the special poverty experience, there may be differences in exploring and analyzing the different dimensions of poverty experience in strengthening the influence of senior managers' influence on corporate social responsibility. Yang (2016) believe that senior managers' poverty experience has a longer-lasting impact on corporate social responsibility performance than age, work background and educational background [8]. The more senior managers suffered from the experience, the stronger the effect will be. Affected by the surrounding poverty culture and the perception of poverty, the poverty environment in the early days of senior managers will gradually have a direct impact on the establishment of early sympathy of senior managers [9]. Of course, it cannot be denied that if senior managers lived in a poor environment, there are possibilities that they were not poor. Thus, the poverty environment has a weaker influence on the sympathy of senior managers. Compared with the poor environment experience, the economic depression and the extreme lack of food caused by the three-year hard period can have a profound impact on the their physical and spiritual memories [10]. The special poverty experience experienced by the early life of senior managers, including the sudden natural disaster, serious illness of family members or family accidents, has a deeper psychological impact on the senior managers. Because resones mentioned above, often brings despair in life or feelings of no other ways to go [11]. Thus, once senior managers have experienced these ups and downs in their early years, their attitudes towards life and society will have greater tolerance and compassion. Hence, from the perspective of the degrees of the poverty experience, the impact of the poverty environment is relatively weak, while the impact of three-year hard period and the special poverty experience is gradually increasing. Based on these, this paper proposes hypothesis 2: Compared with the experience of poverty environment, three-year hard period experience and special poverty experience strengthen the positive correlation between senior managers'influence and corporate social responsibility.

\section{Sample Selection and Research Design}

\subsection{Sample Selection and Data Sources}

This paper takes China's A-share listed companies as research samples from 2012 to 2015. On this basis, the samples are also screened as follows: (1) Excluding financial and insurance companies; (2) Excluding ST and *ST companies; (3) Excluding Each control variable has a missing value and a sample of the associated financial data anomaly. A total of 1796 observations were obtained for the valid samples. There are three main sources of data in this paper: (1) corporate Social Responsibility Performance Indicators data from Runling Global Corporate Social Responsibility Evaluation System; (2) senior managers' impact data indicators from CCTV, First Financial Website, Sina Finance, Fortune Chinese Network, Forbes Chinese Network, Baidu Encyclopedia and related corporate official website, etc., the basic data involved are all collected by manually. Similarly, in order to avoid possible endogenous problems, the senior managers' impact indicators use t-1 data; (3) senior managers' poverty experience data is from the official website of the relevant enterprises, the State Council Office of Poverty Alleviation, the National Bureau of Statistics, Baidu Encyclopedia, Celebrity interviews and biographies, etc.; (4) Relevant financial data mainly comes from Guotaian database and Wande database. The statistical software used in this article is SPSS 22.0.

\subsection{Definition of Variables}

1. Corporate Social Responsibility (CSR). This paper takes the total score of Runling Global Corporate Social Responsibility Rating from 2012 to 2015 as a substitute indicator for measuring the level of corporate social responsibility performance of listed companies. The evaluation data of Runling Global Responsibility Rating Company on the social responsibility performance of listed companies comes from the annual report and social responsibility report issued by related companies. The evaluation system has strong objectivity, large amount of information and high accuracy, it is used by many scholars to measure the level of social responsibility performance of listed companies. The higher the total score of CSR rating is, the higher the level of social responsibility performance of listed companies is. Meanwhile, when conducting the robustness test, this paper uses the ratio of corporate charitable contributions to the total assets of the enterprise (DON) to conduct a robustness test.

2. Executive influence (INF). This paper studies the 
definition of executive influence by four factors: social honor, industry influence, corporate influence and government influence. Among them, social honors, as substitute indicators, are decided by whether the senior managers have received provincial or above awards, the provincial and above awards experience is assigned a value of 1 , otherwise the value is 0 ; the industry influence, as substitute indicators, are decided by whether the senior managers are selected by the provincial or municipal media or the financial website celebrity list. For senior managers who are selected during the tenure, the value is 1 , otherwise the value is 0 ; corporate influence, as substitute indicators, are decided by company's shareholders and employees. Re-election during the tenure means that the executive has obtained the approval of the shareholders and employees, and the value is assigned 1 point, otherwise the value is 0 ; the government influence, as substitute indicators, are decided by whether senior managers are deputies to the NPC, a member of the Chinese People's Political Consultative Conference, or whether have government work experience during the tenure. During the tenure, having the experience above is assigned a value of 1 point, otherwise the value is 0 . Finally, the total score of the four indicators is calculated as a surrogate for executive influence.

3. Poverty experience (POV). The following three types of indexes are selected to form a indicator of executive poverty experience:(1) The character formation of senior managers depends on the development environment of their hometown. The common economic activities, collective memory and spiritual characteristics of the region have an important influence on the early personality formation of senior managers (Zhang Jianjun and Zhang Zhixue, 2006). Taking into account the poverty environment in which the senior management was in the early years, the "National Poverty Counties" identified by the State Council Office of Poverty Alleviation in 2012 as an index. Comparing the birthplace of senior managers with the list of poverty-stricken counties, being selected as "national poverty-stricken counties" the index is assigned 1 point, otherwise it is 0 ; (2) Referring to the measurement methods of Xu Nianxing and Li Zhe (2016), this papaer considers whether the senior managers experienced the "three-year hard period" (1959-1961) as an index. According to the age of childhood in psychology, the age childhood in memory is defined from 4 to 14 years old. Therefore, senior managers born in 1947-1957, the index is assigned 1 point, otherwise it is 0 ; (3) Special poverty experience. Such as sudden natural disasters, family accidents, serious diseases, etc., will also bring pain and suffering to the early years of senior managers, and thus cause family poverty. Therefore, the senior managers experienced a special poverty experience in childhood, this index is assigned 1 point, otherwise it is 0 . The total score that adds the scores of the above three indexes forms a substitute indicator of the early poverty experience of the senior managers.

4. Control variables. Consistent with the previous metrics, and considering the factors that may have an impact on corporate social responsibility, company size (SIZE), profitability (EPS), financial leverage (LEV), property rights (STATE), and age of listing (LISTGE), as control variables for this study are added. In addition, annual dummy variables (YEAR) and industry dummy variables (INDUSTRY) are added to control annual and industry fixed effects.

\subsection{Inspection Model}

In order to verify the hypothesis 1 proposed in this paper, the following least squares regression model (1) is constructed. To verify the hypothesis 2 proposed in this paper, the following (2), (3) and (4) least squares regression models are constructed.

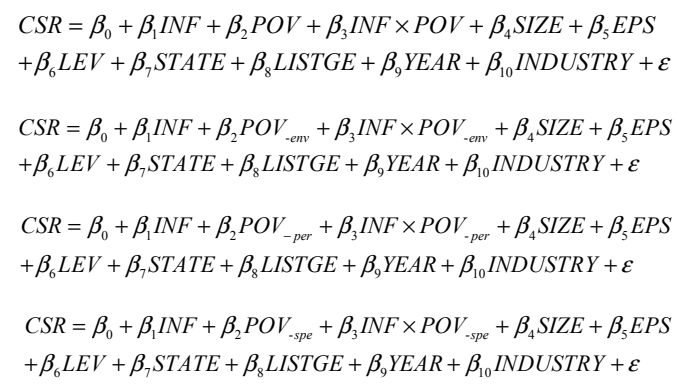

\section{Empirical Test and Analysis}

\subsection{Regression Analysis}

(1) Regression Analysis of the interaction between managers' influence and Poverty experience

To test the interaction of senior managers' influence and poverty experience on corporate social responsibility performance, regression analysis was conducted within selected samples, as shown in Table 1. According to the regression results, the coefficient of interaction (INF*POV) between senior managers' influence and poverty experience is 0.100 , and it is significantly positively correlated with corporate social responsibility performance at $1 \%$. It shows that managers' influence and poverty experience have complementary effects influencing corporate social responsibility performance. That is to say, poverty experience reinforces the impact of managers' influence on corporate social responsibility performance. The greater the influence of managers is, more likely the managers with poverty experience will cherish trust and prestige coming from the outside, and are more willing to maintain and strengthen their personal influence by becoming active on their social responsibilities. At the same time, the greater the influence of managers is, the greater the society's expectations for managers will be, the more social responsibility of the companies will have to face, the more likely the managers will put themselves in others' shoes. Thus, Hypothesis 1 is verified. 
Table 1. Sample regression analysis results.

\begin{tabular}{lll}
\hline \multirow{2}{*}{ Variable } & CSR & \\
\cline { 2 - 3 } & Coefficient & Value (T) \\
\hline C & $-43.729^{* * *}$ & -9.419 \\
INF & $0.097^{* * *}$ & 2.751 \\
POV & $0.087^{* * *}$ & 3.852 \\
INF*POV & $0.100^{* * *}$ & 2.682 \\
SIZE & $0.455^{* * *}$ & 16.631 \\
EPS & 0.001 & 0.018 \\
LEV & $-0.165^{* * *}$ & -6.682 \\
STATE & $0.079^{* * *}$ & 3.727 \\
LISTGE & $-0.091^{* * *}$ & -4.433 \\
YEAR & control & \\
INDUSTRY & control & \\
Value (F) & $104.486^{* * *}$ & \\
Adj. R2 & 0.316 & \\
\hline
\end{tabular}

\begin{tabular}{lll}
\hline \multirow{2}{*}{ Variable } & CSR & \\
\cline { 2 - 3 } & Coefficient & Value (T) \\
\hline $\mathrm{N}$ & 1796 & \\
\hline
\end{tabular}

Note: $* * *$ indicates significant at $1 \%$ level; $* *$ indicates significant at $5 \%$ level; * indicates significant at $10 \%$ level.

(2) Regression analysis of interaction effects between managers' influence and poverty experience is to do a further research about the interaction between manager influence and poverty experience. This paper conducts regression tests on the interaction between manager influence and sub-dimensional index of poverty experience. The regression results are shown in Table 2.

Table 2. Sample regression analysis results.

\begin{tabular}{|c|c|c|c|c|c|c|}
\hline \multirow{3}{*}{ Variable } & \multicolumn{6}{|l|}{ CSR } \\
\hline & \multicolumn{2}{|l|}{ (i) } & \multicolumn{2}{|l|}{ (ii) } & \multicolumn{2}{|l|}{ (iii) } \\
\hline & Coefficient & Value (T) & Coefficient & Value (T) & Coefficient & Value (T) \\
\hline $\mathrm{C}$ & $-51.788 * * *$ & -11.201 & $-49.893 * * *$ & -10.715 & $-48.831 * * *$ & -10.611 \\
\hline INF & $0.155^{* * *}$ & 7.361 & $0.122 * * *$ & 4.793 & $0.144 * * *$ & 7.024 \\
\hline POV-env & $0.117 * * *$ & 3.415 & & & & \\
\hline POV-per & & & $0.067 * *$ & 2.262 & & \\
\hline POV-spe & & & & & $0.142 * * *$ & 3.220 \\
\hline INF*POV-env & 0.002 & 0.059 & & & & \\
\hline INF*POV-per & & & $0.072 * *$ & 2.118 & & \\
\hline INF*POV-spe & & & & & $0.083 * * *$ & 3.855 \\
\hline SIZE & $0.503 * * *$ & 18.410 & $0.493 * * *$ & 17.931 & $0.484 * * *$ & 17.805 \\
\hline EPS & 0.006 & 0.280 & 0.001 & 0.044 & 0.002 & 0.097 \\
\hline LEV & $-0.179 * * *$ & -7.113 & $-0.174 * * *$ & -6.896 & $-0.162 * * *$ & -6.467 \\
\hline STATE & $0.075 * * *$ & 3.489 & $0.080 * * *$ & 3.705 & $0.080 * * *$ & 3.705 \\
\hline LISTGE & $-0.081 * * *$ & -3.874 & $-0.098 * * *$ & -4.667 & $-0.080 * * *$ & -3.867 \\
\hline YEAR & control & & control & & control & \\
\hline INDUSTRY & control & & control & & control & \\
\hline Value (F) & $92.914 * * *$ & & $92.864 * * *$ & & $98.400 * * *$ & \\
\hline Adj. R2 & 0.291 & & 0.290 & & 0.303 & \\
\hline $\mathrm{N}$ & 1796 & & 1796 & & 1796 & \\
\hline
\end{tabular}

Note: $* * *$ indicates significant at $1 \%$ level; ** indicates significant at $5 \%$ level; * indicates significant at $10 \%$ level.

(i) is the regression results of interaction between senior managers' influence and their early poverty environment The regression coefficient of manager influence is 0.155 , which is significantly positively correlated with corporate social responsibility performance. The regression coefficient of poverty experience is 0.117 , and it is also significantly positively correlated with corporate social responsibility performance. All of this indicates that the influence of managers and poverty experience have a significant positive impact on corporate society responsibility performance. The results are consistent with the relevant findings of the previous chapters. However, the coefficient of interaction (INF*POV-env) between senior managers' influence and the poor environment in the early days is 0.002 , which is positively correlated but not significant. It shows that senior managers' poverty environment experience plays a weak role in strengthening the relationship between senior managers' influence and corporate social responsibility performance. The reasons may be found in the selected samples. Some managers lived in poverty-stricken counties in the early days, but the condition of the family is relatively good, thus the influence of the surrounding poverty environment is limited which caused the limited influence regarding the formation of their values.

(ii) is the result of the interaction between senior managers' influence and the three-year hard period. It can be found that the regression coefficient of senior managers' influence is 0.122 , and the regression coefficient of manager poverty experience is 0.067 . Both of them have a significant positive correlation with corporate social responsibility performance, which is consistent with the previous research conclusions. Observing the influence of managers and the three-year hard period, the (INF*POV-per) coefficient is 0.072 , and at the $5 \%$ level, it is significantly positively correlated with corporate social responsibility performance, indicating that the three-year hard period experience has enhanced effects. The enhanced effects also reflect how profound the harship is This hardship has an impact on the their early psychology and is beneficial to senior managers'. formation of sympathy and the formation of being considerate. Considering the influence of managers, the hard period of three years, and the positive interaction coefficient of these two factors, it suggests that the 
influence of managers and the experience have complementary effects influencing corporate social responsibility performance This further supports the previous research conclusions in this paper.

(iii) is the regression result of the interaction between senior managers' influence and special poverty experience. It is shown (from the regression results) that the regression coefficient of the senior managers' influence is 0.144 , and the regression coefficient of the special poverty experience is 0.142 . Both of them are significantly positively correlated with the fulfillment of corporate social responsibility, which is consistent with the previous research conclusions. The coefficient of interaction between managers and special poverty experience (INF*POV-spe) is 0.083 , and it is significantly positively correlated with corporate social responsibility performance at $1 \%$, explaining that the special difficulties have strengthened the senior managers' influence on corporate social responsibility performance. Managers with special difficulties experience, sudden disasters, serious illnesses or family accidents which have a profound impact on the personality and psychology of senior managers, are profoundly psychologically impacted.

By comparing the effects of senior manager' influence with poor environmental experience, three-years hard period experiences and special poverty experiences, we found that not only from the perspective of the coefficient comparison but also the significance, special poverty experience and three-year hard experience, have stronger effects on strengthening the implementation of corporate social responsibility through the influence of senior managers. In addition, it also reflects that the higher the intensity of poverty experience in the early years is, the stronger the strengthening effect will be in the later stage. Thus, hypothesis 2 is verified.

\subsection{Robustness Test}

In order to examine the accuracy of the above research conclusions, this paper considers the relationship between corporate charitable donations and corporate social responsibility by changing the substitute indexes of corporate social responsibility performance. At the same time, in order to ensure the comparability of charitable contributions among different enterprises, the proportion of donations to the total assets of the enterprise is used as an substitute index for the fulfillment of corporate social responsibility, and the robustness of the interaction between senior managers' influence and poverty experience. The regression results of the robustness test which was conducted on the senior managers' influence, the experience of poverty and the interaction between the two, are shown in Table 3 .

Table 3. Robustness test results.

\begin{tabular}{lll}
\hline \multirow{2}{*}{ Variable } & CSR & \\
\cline { 2 - 3 } & Coefficient & Value (T) \\
\hline C & $0.647 * * *$ & 12.147 \\
INF & $0.182^{* * *}$ & 3.463 \\
POV & $0.415 * * *$ & 5.488 \\
INF*POV & $0.238^{* * *}$ & 2.711 \\
SIZE & -0.011 & -0.184 \\
EPS & $0.180 * * *$ & 4.274 \\
LEV & $-0.101 * *$ & -2.043 \\
STATE & $0.262 * * *$ & -5.885 \\
LISTGE & $-0.151 * * *$ & -3.630 \\
YEAR & control & \\
INDUSTRY & control & \\
Value (F) & $24.092 * * *$ & \\
Adj. R2 & 0.275 & \\
N & 486 & \\
\hline
\end{tabular}

Note: $* * *$ indicates significant at $1 \%$ level; $* *$ indicates significant at $5 \%$ level; * indicates significant at $10 \%$ level.

As shown in Table 3, the coefficient of senior managers' influence (INF) is 0.182 , and is significantly positively correlated with corporate charitable contributions at the $1 \%$ level; the coefficient of poverty experience (POV) is 0.415 , and at the level of $1 \%$ which is positively correlated with corporate charitable contributions; the coefficient of interaction between the two is 0.238 , and is significantly positively correlated with corporate charitable contributions at the $1 \%$ level. From the regression results, the significance of the relevant variables has not changed. This further validates the hypothesis 1 proposed in this paper.

The regression results of the robustness test which was conducted on the interaction effect between the senior managers' influence and the sub-index of poverty experience are shown in Table 4.

Table 4. Robustness test results.

\begin{tabular}{|c|c|c|c|c|c|c|}
\hline \multirow{3}{*}{ Variable } & \multicolumn{6}{|l|}{ DON } \\
\hline & \multicolumn{2}{|l|}{ (i) } & \multicolumn{2}{|l|}{ (ii) } & \multicolumn{2}{|l|}{ (iii) } \\
\hline & Coefficient & Value (T) & Coefficient & Value (T) & Coefficient & Value (T) \\
\hline $\mathrm{C}$ & $0.613 * * *$ & 11.415 & $0.617 * * *$ & 11.117 & $0.594 * * *$ & 11.275 \\
\hline INF & $0.137 * * *$ & 2.980 & $0.189 * * *$ & 3.597 & $0.152 * * *$ & 3.446 \\
\hline POV-env & $0.210 * * *$ & 2.609 & & & & \\
\hline POV-per & & & $0.186 * * *$ & 2.836 & & \\
\hline POV-spe & & & & & $0.417 * * *$ & 5.018 \\
\hline INF*POV-env & 0.062 & 0.747 & & & & \\
\hline INF*POV-per & & & $0.135^{*}$ & 1.798 & & \\
\hline INF*POV-spe & & & & & $0.254 * * *$ & 3.015 \\
\hline SIZE & 0.041 & 0.713 & 0.030 & 0.499 & 0.052 & 0.909 \\
\hline EPS & $0.212 * * *$ & 4.972 & $0.214 * * *$ & 4.988 & $0.182 * * *$ & 4.277 \\
\hline LEV & $-0.143 * * *$ & -2.823 & $-0.112 * *$ & -2.185 & $-0.107 * *$ & -2.146 \\
\hline STATE & $-0.296 * * *$ & -6.539 & $-0.283 * * *$ & -6.115 & $-0.269 * * *$ & -5.996 \\
\hline
\end{tabular}




\begin{tabular}{|c|c|c|c|c|c|c|}
\hline \multirow{3}{*}{ Variable } & \multicolumn{6}{|l|}{ DON } \\
\hline & \multicolumn{2}{|l|}{ (i) } & \multicolumn{2}{|l|}{ (ii) } & \multicolumn{2}{|l|}{ (iii) } \\
\hline & Coefficient & Value (T) & Coefficient & Value (T) & Coefficient & Value (T) \\
\hline LISTGE & $-0.151 * * *$ & -3.537 & $-0.168 * * *$ & -3.910 & $-0.150 * * *$ & -3.562 \\
\hline YEAR & control & & control & & control & \\
\hline INDUSTRY & control & & control & & control & \\
\hline Value (F) & $20.204 * * *$ & & $19.013^{* * *}$ & & $22.996 * * *$ & \\
\hline Adj. R2 & 0.240 & & 0.229 & & 0.265 & \\
\hline $\mathrm{N}$ & 486 & & 486 & & 486 & \\
\hline
\end{tabular}

Note: *** indicates significant at $1 \%$ level; ** indicates significant at $5 \%$ level; * indicates significant at $10 \%$ level.

(i) is the regression result of the interaction effect between senior managers' influence and poverty environment on corporate charitable donation. It can be revealed from the results that the coefficient of senior managers' influence (INF) is 0.137 , and it is significantly positively correlated with corporate charitable contributions at $1 \%$ level; the coefficient of poverty experience of senior managers (POV-env) is 0.210 , and there is a significant positive correlation with corporate charitable contributions at $1 \%$; the interaction between senior managers' influence and poor environment (INF) *POV-env) has a coefficient of 0.062 , which is positively correlated with corporate charitable contributions but not significant, which is consistent with the previous findings.

(ii) is the result of the impact of interaction between senior managers' influence and the poverty period experience on the corporate charitable donations. It is shown that the coefficient of senior managers' influence (INF) is 0.189 , which is positively correlated with the corporate charitable contribution, at the level of $1 \%$. The coefficient of poverty (POV-per) experience is 0.186 , and there is a significant positive correlation with corporate charitable contributions at $1 \%$. The coefficient of the interaction between senior managers' influence and poverty period (The coefficient of INF*POV-per) is 0.135 , which is significantly positively correlated with corporate charitable contributions at the $10 \%$ level. The results further validate the previous conclusions.

(iii) is the regression result of the interaction effect between senior managers' influence and special poverty experience on corporate charitable donation. It is shown that the coefficient of senior managers' influence (INF) is 0.152 which is positively correlated with the corporate charitable donation, at the level of $1 \%$. The coefficient of special poverty-stricken experience experience of senior managers (POV-spe) is 0.417 , it is a significantly positively correlated with corporate charitable contributions at the level of $1 \%$. The coefficient of the interaction (INF*POV-spe) is 0.254 which is significantly positively correlated with corporate charitable contributions at the $1 \%$ level. These resultes further validate the conclusions of the previous study.

From the above three conclusions of the robustness tests, it can be revealed that the coefficient of interaction between senior managers' influence, poverty environment, three years of difficult period experience and special poverty experience is gradually increasing. The results further verify the hypothesis 2 .

\section{Conclusions and Inspiration}

The study found that senior managers' influence and poverty experience have a complementary relationship for the fulfillment of corporate social responsibility, i.e. the early poverty experience helps to strengthen the positive correlation between senior managers' influence and corporate social responsibility. The greater the senior managers' influence is, the higher the level of social responsibility will be. On the one hand, it is suggested that the greater the senior managers' influence is, the higher the expectations of society will be, the more likely that the sense of social responsibility of senior managers will be triggered, and the stronger the original motivation to actively fulfill social responsibility will be. On the other hand, it could be shown that the greater the senior managers' influence is, the more likely they would cherish their reputation and respond positively to external social responsibility needs as they experienced ups and downs. This paper also analyzes the interaction effects of senior managers' influence and poverty experience, including poverty environment experience, three-years hard period experience and special poverty experience. Based on the analysis: the poverty environment in the early stage of senior managers is less significant. The three-year hard period and the special poverty experience are significantly positively correlated with the fulfillment of corporate social responsibility, indicating that, in the early stage, the higher the poverty degree of the senior managers is, the greater the enhancemene of fulfilling corporate social responsibility performance caused by senior managers' influence will be.

The conclusions of this paper have important theoretical and practical significance. In theory, at present, domestic and international research has not explored the impact on senior managers' social responsibility performance based on the interaction of their influence and poverty experience. Therefore, as a new attempt, this paper can provide theoretical and methodological references for subsequent researches. In practice, the research in this paper can provide theoretical support and empirical evidence for governments and enterprises to strengthen the social responsibility awareness education and incentives and to correct the personal behaviors of senior managers.

\section{References}

[1] Hofstede, G. The cultural relativity of the quality of life concept [J]. Academy of Management Review, 1984 (07): 389-398. 
[2] Benmelech E., and C. Frydman. Military CEOs [J]. Journal of Financial Economics, 2015 (117): 43-59.

[3] Joe, J., H. Louis, and D. Robinson. Managers' and Investors' Responses to Media Exposure of Board Ineffectiveness [J]. Journal of Financial and Quantitative Analysis, 2009, 44 (3): 579-605.

[4] Slater, D., Dixon Fowler, H. CEO International Assignment Experience and Corporate Social Performance [J]. Journal of Business Ethics, 2009, 89 (3): 473-489.

[5] Kuhnen C, Niessen A. Is Executive Compensation Shaped by Public Attitudes? [R]. Evanston: Northwestern University, 2009.

[6] Enikolopov, R., Petrova, M., Zhuravskaya, E. Media and Political Persuasion: Evidence from Russia [J]. American Economic Review, 2011, 101 (7): 3253-3285.

[7] Porter M E, Kramer M R. Strategy and Society: The Link between Competitive Advantage and Corporate Social Responsibility [J]. Harvard Business Review, 2006 (12): 36-37.

[8] Yang Junjie, Cao Guohua. CEO Reputation, Earnings Management and Investment Efficiency [J]. Soft Science, 2016, 30 (11): 71-77.

[9] Jennifer, F., H. Allen, R. Shivaram. CEO Reputation and Earnings Quality [J]. Contemporary Accounting Research, 2008, 25 (1): 109-147.
[10] Graham, J., Harvey, and M. Puri. Capital Allocation and Delegation of Decision making Authority within Firms [J]. Journal of Financial Economics, 2015, (115) 449-470.

[11] Malmendier, U., Tate, and Yan. Overconfidence and Early life Experiences: The Effect of Managerial Traits on Corporate Financial Policies [J]. Journal of Finance, 2011 (66): 1687-1733.

[12] Benson. What Determines Success? Examining The Human, Financial and Social Capital of Jamaican Microentrepreneurs [J]. Journal of Business Venturing, 1998 (13): 371-394.

[13] Hui Zhengyi. Corporate Social Responsibility Top Management Influence [N]. China Business News, May 2008 (C05).

[14] Hahn, A., and B. Gawronski. Implicit Social Cognition [J]. International Encyclopedia of the Social and Behavioral Sciences, 2015, (17): 714-720.

[15] Brammer S J, Pavelin S. Building a Good Reputation [J]. European Management Journal, 2004 (12): 704-713.

[16] Zyglidopoulos, Georgiadis. Does Media Attention Drive Corporate Social Responsibility? [J]. Journal of Business Research, 2012, 65 (11): 1622-1627.

[17] Ponzi L J, Fombrun C J, Gardberg N A. Rep Trak Pulse: Conceptualizing and Validating a Short Form Measure of Corporate Reputation [J]. Corporate Reputation Review, 2011, 14 (1): 15-35. 